\title{
Article \\ Effects of Electrolyte Supplements on Body Water Homeostasis and Exercise Performance during Exhaustive Exercise
}

\author{
Dong-Hun Choi ${ }^{1}$, Joon-Yong Cho ${ }^{1,2}$, Jung-Hoon Koo ${ }^{1,2}$ and Tae-Kyung Kim ${ }^{1,3,4, *(D)}$ \\ 1 Department of Exercise Biochemistry, Korea National Sport University, Seoul 05541, Korea; \\ choihundong@knsu.ac.kr (D.-H.C.); chojy86@knsu.ac.kr (J.-Y.C.); mt634@knsu.ac.kr (J.-H.K.) \\ 2 Department of Exercise Training for Health Care \& Management, Korea National Sport University, \\ Seoul 05541, Korea \\ 3 Department of Sport Science Institute, Korea National Sport University, Seoul 05541, Korea \\ 4 Department of Physical Education, Korea National Sport University, Seoul 05541, Korea \\ * Correspondence: spt21@knsu.ac.kr; Tel.: +82-2-410-6955
}

check for

updates

Citation: Choi, D.-H.; Cho, J.-Y.; Koo, J.-H.; Kim, T.-K. Effects of Electrolyte Supplements on Body Water

Homeostasis and Exercise

Performance during Exhaustive

Exercise. Appl. Sci. 2021, 11, 9093

https://doi.org/10.3390/

app11199093

Academic Editor:

Alessandra Durazzo

Received: 31 August 2021

Accepted: 26 September 2021

Published: 29 September 2021

Publisher's Note: MDPI stays neutral with regard to jurisdictional claims in published maps and institutional affiliations.

Copyright: (C) 2021 by the authors Licensee MDPI, Basel, Switzerland. This article is an open access article distributed under the terms and conditions of the Creative Commons Attribution (CC BY) license (https:// creativecommons.org/licenses/by/ $4.0 /)$
Abstract: This study aimed to compare the physiologic effects of regular water consumption to those of electrolyte drink consumption in exercise capacity and recovery after exhaustive exercise. The participants were 10 healthy young men who exercised on a treadmill before and after receiving regular water and an electrolyte drink (3RINK) four weeks later. A 250-mL fluid volume was ingested $30 \mathrm{~min}$ before exercise and immediately after. Body composition, water metabolizing hormones, and body electrolytes were analyzed at rest (R), immediately after exercise (P0), and $1 \mathrm{~h}$ after exercise (P1). Moreover, serum lactic acid levels were measured to determine recovery. Total body water, intracellular, and extracellular water levels were higher after consuming 3RINK at P0 than at R. There was no interaction effect between the types of fluids and antidiuretic hormone, aldosterone, and renin levels. Hematocrit levels showed an interaction effect between the type of fluid and period. Sodium levels were significantly different between the different types of fluids at P0 and P1. Finally, an interaction effect was noted between each type of fluid and serum lactate levels. Thus, 3RINK intake before and after exhaustive exercise increased body capacity to retain water, improved exercise ability, and reduced exercise-related fatigue.

Keywords: exercise; electrolyte; body water homeostasis; antidiuretic hormone

\section{Introduction}

Our bodies are composed of $60-70 \%$ water, $40 \%$ of which is contained within cells, and is an essential factor in sustaining life. Water acts as a solubilizer of minerals, amino acids, vitamins, glucose [1], and electrolytes, which are pivotal to the control of body homeostasis. However, the importance of research on proper water intake is emphasized because the intake of adequate water to maintain water homeostasis is greatly influenced by sex, response according to the external temperature, calorie consumption, concentratingdiluting capacities of the kidneys, and water loss via excretions and secretions [2]. Physical activities, such as exercise, change the electrolyte levels and water homeostasis [3], and the lack of water and electrolytes results in dehydration, increased blood viscosity, and impaired oxygen tissue delivery [4]. In a study by Rehrer [5], excessive water deprivation and severe dehydration during American football training may possibly lead to death. Thus, dehydration reduces exercise performance because of reduced blood flow to the muscles or skin during exercise and accelerates hyperthermia because of prolonged exercise. Associated physiologic changes include decreased plasma volume, blood pressure, and cardiac output; decreased blood flow to the kidneys; and impaired regulation of body temperature [6,7]. During exercise, electrolyte and water homeostases are maintained by the water-regulating hormone known as the antidiuretic hormone (ADH) along with the renin-angiotensin-aldosterone system [7]. $\mathrm{ADH}$ is secreted from the posterior pituitary 
gland to suppress water loss because of sweating as a result of exposure to high temperature or exercise, whereas aldosterone, secreted from the adrenal cortex, plays a role in preserving $\mathrm{Na}^{+}$in the extracellular fluid and increasing the excretion of $\mathrm{K}^{+}$in urine [8]. During exercise, the body loses water and electrolytes and, if only water is supplemented in response, plasma sodium concentration and osmotic pressure may decrease significantly. In severe cases, hyponatremia may occur, which can cause mental confusion and seizures $[9,10]$.

In particular, a study conducted on marathon runners engaging in a type of endurance exercise, reported that dehydration during exercise caused excessive secretion of $\mathrm{ADH}$, aldosterone, and renin activity, resulting in increased plasma osmotic pressure, reduced plasma volume, and eventually hyponatremia [11]. However, according to a previous study, drinking water during exercise required an increased amount of blood to digest and absorb moisture and, therefore, it was considered to negatively affect muscles. In addition, there was an increased perception that water intake during exercise decreases exercise performance because of abdominal bloating, stomachache, and discomfort caused by stomach fluctuations [12].

Therefore, various studies have established the use of an optimal method to prevent dehydration and maintain proper water and electrolyte homeostases during daily life or exercise $[13,14]$. Recently, ion sports drinks and electrolyte drinks have become popular as they can replace electrolyte loss during exercise [15]. Consumption of water containing electrolytes before exercise has been shown to effectively maintain electrolyte homeostasis and conserve blood volume after exercise [16], whereas a one-time intake of ion sports drinks prevents post-workout lactic acid accumulation, accelerates heart rate reduction and water retention, and adds various minerals essential for optimal metabolism [17]. In contrast, a one-time use of sodium during exercise did not show significant advantages [18]. To provide adequate hydration during exercise, a combination of various electrolytes, strategic eating habits, and sodium are more important than individual components [19].

The aforementioned studies suggest the importance of replenishing water and minerals before and after exercise in improving exercise capacity and expediting recovery. However, research on the proper timing of hydration, electrolyte components, and water metabolites for improving exercise performance and recovery is insufficient. Therefore, the purpose of this study was to suggest an efficient hydration method by analyzing the body's water utilization ability, recovery ability through water intake, and exercise ability according to the intake of electrolyte drinks rich in sodium and potassium before and after performing exhaustive exercise.

\section{Materials and Methods}

\subsection{Participants}

Ten male participants in their 20s volunteered to participate in the study; all of them had no health issues and had signed an informed consent. The participants agreed to abstain from strenuous exercise, alcohol consumption, and smoking and adhere to a specific diet. The physical characteristics of the participants were as follows: age: $25.40 \pm 1.51$ years; height: $176.93 \pm 4.53 \mathrm{~cm}$; weight: $81.98 \pm 10.13 \mathrm{~kg}$; and body mass index: $26.14 \pm 3.19 \mathrm{~kg} / \mathrm{m}^{2}$. The research protocol was approved by the Bioethics Committee of the Korea National Sports University (1263-202103-BR-004-01).

\subsection{Study Design}

For the purposes of the study, the participants completed two experiments with a 4-week interval according to the following Figure 1 study protocol: 

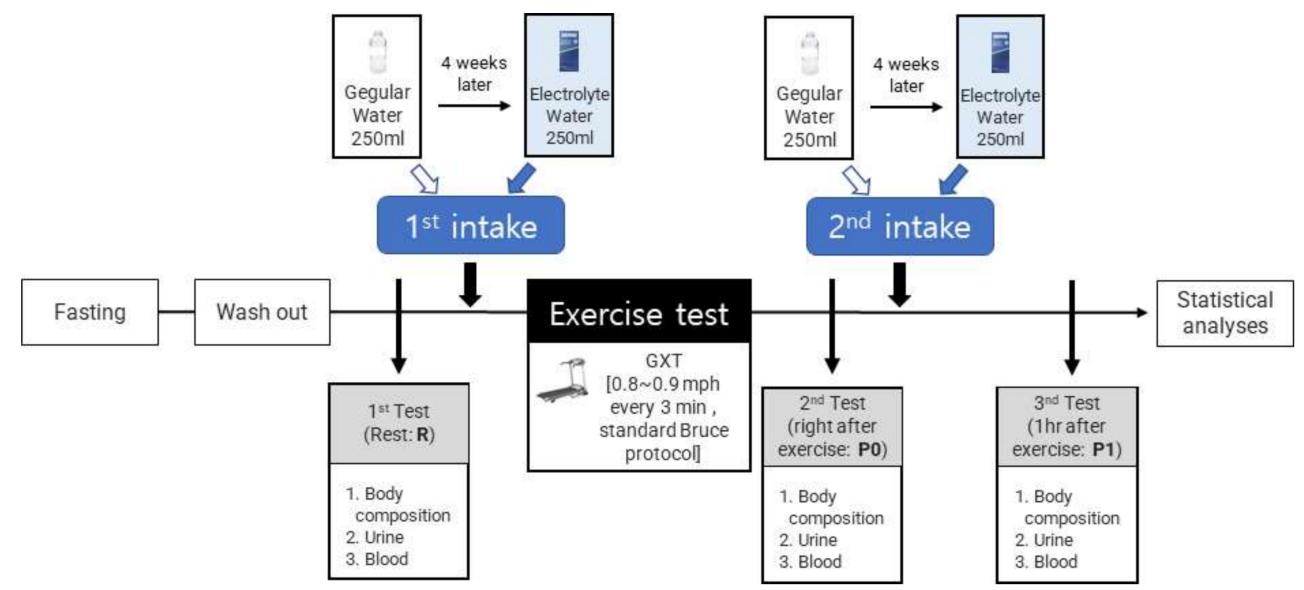

Figure 1. Study design.

\subsection{Hydration Treatment}

Before the ingestion of fluids, the participants fasted for $12 \mathrm{~h}$ under the same conditions. The fluids used in this study were regular water $\left(\mathrm{CON} ; \mathrm{Na}^{+}: 1.5 \mathrm{mg}, \mathrm{K}^{+}: 0.4 \mathrm{mg}, \mathrm{Mg}^{++}\right.$: $2.6 \mathrm{mg}$ ) by L (L Inc., San Francisco, CA, USA) or electrolyte water (3RINK; Interstellar Co., Ltd., Hokkaido, Japan). The nutritional components of 3RINK are listed in Table 1. This drink was in a powder form. As per the instructions indicated in the product manual, one sachet $(10 \mathrm{~g})$ was diluted in $250 \mathrm{~mL}$ of water. After shaking to completely dissolve the powder of 3RINK, it was hydration for 5 to $10 \mathrm{~min}$. This volume $(250 \mathrm{~mL})$ was consumed twice. After fasting for $12 \mathrm{~h}$, the participants received $500 \mathrm{~mL}$ of $\mathrm{CON}$ at $2 \mathrm{~h}$ before the first test. The first hydration was $250 \mathrm{~mL}$ of $\mathrm{CON}$ at $30 \mathrm{~min}$ before the exercise test. For the second hydration, $250 \mathrm{~mL}$ of $\mathrm{CON}$ was ingested immediately after the second examination. After four weeks, the fluids were changed to 3RINK and hydration was performed following the same process.

Table 1. 3RINK nutrition components (Based on 1 sachet [10 g]).

\begin{tabular}{ccccccc}
\hline Variable & Sodium $\left(\mathrm{Na}^{+}\right)$ & Potassium $\left(\mathbf{K}^{+}\right)$ & Magnesium $\mathbf{( \mathbf { M g } ^ { + + } )}$ & Carbohydrates & Sugar & Vitamin $\mathbf{C}$ \\
\hline Amount & $350 \mathrm{mg}$ & $190 \mathrm{mg}$ & $40 \mathrm{mg}$ & $8.2 \mathrm{~g}$ & $5.8 \mathrm{~g}$ & $100 \mathrm{mg}$ \\
\hline
\end{tabular}

\subsection{Body Composition}

Three body composition tests were performed. The first test (Rest; R) was performed at $2 \mathrm{~h}$ after wash out, and the second test (right after exercise; P0) was performed immediately after the exercise test. Finally, the third test ( $1 \mathrm{~h}$ after exercise; P1) was conducted at $1 \mathrm{~h}$ after ingestion of the second fluid. The body weight (BW), total body water (TBW), intracellular water (ICW), extracellular water (ECW), body fat mass (BFM), percent body fat, and skeletal muscle mass were measured using eight-polar bioelectrical impedance analysis with multiple impedance frequencies (Inbody 770, Biospace Co., Seoul, Korea).

\subsection{Urine and Blood}

Urine and blood analyses were performed three times in the same way as for the body composition tests. First, for the urine measurement, the participants' urine samples were collected in a dedicated container, and the volume was measured in $\mathrm{mL}$. After fasting for $12 \mathrm{~h}, 10 \mathrm{~mL}$ of blood was collected from the upper arm veins of the study participants, incubated at room temperature for $30 \mathrm{~min}$, and centrifuged ( $3000 \mathrm{rpm}, 10 \mathrm{~min}$ ) to separate the serum and plasma. Serum and plasma were refrigerated $\left(4^{\circ} \mathrm{C}\right)$ and kept frozen $\left(-80^{\circ} \mathrm{C}\right)$ until analysis. Among the blood components, lactic acid, a factor related to recovery after exercise, was measured for five times (before exercise, immediately after exercise, and at 
5, 10, and $15 \mathrm{~min}$ after exercise). All blood samples were analyzed by the Green Cross Medical Foundation (Gyeonggi-do, Korea).

\subsection{Exercise Test}

Exhaustive exercise was performed according to the American College of Sports Medicine guidelines. Maximum oxygen comsumption $\left(\mathrm{VO}_{2} \mathrm{max}\right)$, maximum heart rate (HRmax), minute ventilation (VE), respiratory exchange ratio (RER), and exercise time were measured during a maximal graded exercise using a computerized cardiopulmonary metabolic system (Cosmed Treadmill T170 DE, Quark CPET, Cosmed Co., Rome, Italy). Before testing, the metabolic system was calibrated according to the manufacturer's instructions. The participants performed a 3-min warm-up at $1.7 \mathrm{mph}$ with $0 \%$ grade to familiarize themselves with the procedure. This was immediately followed by a gradual increase in treadmill velocity and grade by approximately $0.8-0.9 \mathrm{mph}$ every $3 \mathrm{~min}$ according to the standard Bruce protocol.

\subsection{Hypothesis and Study Limits}

We hypothesized that there would be a difference in body composition, waterregulating hormone levels, body electrolyte composition, aerobic exercise ability, and recovery ability between the groups and the periods depending on when the fluids were administered. Our study had some limitations. First, the participants were only 10 men in their 20s. Moreover, the individuals' dietary habits and genetic characteristics were not examined. Finally, the administered regular water was a product of L company, which was available in the market.

\subsection{Statistical Analyses}

For the collected data, the mean and standard error of the results were calculated using SPSS 24.0 (IBM Corp., Armonk, NY, USA). Repeated two-way analysis of variance was performed to identify the difference between the groups $(2) \times$ times (3), and if there was an interaction effect, the main effect was verified. Independent $t$-tests and paired $t$-tests were performed to verify changes over time between and within the groups. An $\alpha$-value $<0.05$ was considered statistically significant.

\section{Results}

\subsection{Differences in Body Composition According to the Type of Fluid and Intake Period}

Table 2 shows the results of the analysis of body composition according to the type of fluids and intake period. First, in the time interval between R and P0 (P0-R), the comparison between CON and 3RINK revealed significant changes in BFM $(t=2.280$, $p=0.035)$, ICW $(\mathrm{t}=-2.656, p=0.016)$, and ECW $(\mathrm{t}=-2.964, p=0.008)$ but no differences in the other variables. In addition, for the time interval between P1 and P0 (P1-P0), there was no difference between the two types of fluids for any of the variables.

Table 2. Body composition according to the type of fluids and intake period.

\begin{tabular}{ccccccccc}
\hline & CON $(\boldsymbol{n}=\mathbf{1 0})$ & \multicolumn{2}{c}{ 3RINK $(\boldsymbol{n}=\mathbf{1 0})$} & & & \multicolumn{2}{c}{ CON $(\boldsymbol{n}=\mathbf{1 0})$} & \multicolumn{3}{c}{ 3RINK $(\boldsymbol{n}=\mathbf{1 0})$} \\
\cline { 2 - 9 } & P0-R & P0-R & $\mathbf{t}$ & $\boldsymbol{p}$ & P1-P0 & P1-P0 & $\mathbf{t}$ & $\boldsymbol{p}$ \\
\hline BW (kg) & $-0.40 \pm 0.14$ & $-0.27 \pm 0.13$ & -0.667 & 0.513 & $0.07 \pm 0.08$ & $0.17 \pm 0.08$ & -0.896 & 0.382 \\
SMM (kg) & $-0.40 \pm 0.37$ & $-0.21 \pm 0.15$ & -0.473 & 0.642 & $0.20 \pm 0.37$ & $0.55 \pm 0.18$ & -0.842 & 0.411 \\
BFM (kg) & $0.66 \pm 0.22$ & $-0.17 \pm 0.29$ & 2.280 & $0.035^{*}$ & $-0.68 \pm 0.25$ & $-0.53 \pm 0.26$ & -0.411 & 0.686 \\
PBF (\%) & $0.93 \pm 0.28$ & $1.15 \pm 1.30$ & -0.165 & 0.871 & $-0.90 \pm 0.30$ & $-0.71 \pm 0.32$ & -0.428 & 0.673 \\
TBW (L) & $-0.76 \pm 0.17$ & $-0.08 \pm 0.15$ & -2.944 & 0.009 & $0.52 \pm 0.18$ & $0.5 \pm 0.19$ & -0.154 & 0.880 \\
ICW (L) & $-0.53 \pm 0.13$ & $-0.09 \pm 0.10$ & -2.656 & $0.016^{*}$ & $0.38 \pm 0.13$ & $0.33 \pm 0.12$ & 0.283 & 0.781 \\
ECW (L) & $-0.23 \pm 0.05$ & $0.01 \pm 0.06$ & -2.964 & $0.008^{*}$ & $-0.86 \pm 0.96$ & $0.18 \pm 0.07$ & -1.079 & 0.295 \\
ECW / ICW ratio & $0.53 \pm 0.08$ & $0.06 \pm 0.43$ & 1.072 & 0.298 & $-0.71 \pm 0.98$ & $0.38 \pm 0.16$ & -1.094 & 0.288 \\
Urine (mL) & $-74.00 \pm 32.05$ & $-85.50 \pm 14.38$ & 0.327 & 0.747 & $10.00 \pm 13.19$ & $-1.00 \pm 6.62$ & 0.746 & 0.466 \\
\hline
\end{tabular}




\subsection{Differences in Water-Regulating Hormones According to the Timing of Fluid Intake}

Figure 2 shows the results of the analysis of water-regulating hormones according to the type of fluid and the intake period. $\mathrm{ADH}$, aldosterone, and renin showed no interaction effect (ADH: $\mathrm{F}=0.285, p=0.606$; aldosterone: $\mathrm{F}=0.230, p=0.795$; renin: $\mathrm{F}=3.225, p=0.088$ ). However, in a time-dependent analysis, both aldosterone (R-P0: $\mathrm{t}=-3.319, p=0.009$; P0-P1: $\mathrm{t}=2.982, p=0.015)$ and renin $(\mathrm{R}-\mathrm{P0}: \mathrm{t}=-6.140, p=0.001 ; \mathrm{P} 0-\mathrm{P} 1: \mathrm{t}=5.548, p=0.001)$ changed significantly with CON, whereas all three hormones (i.e., $\mathrm{ADH}[\mathrm{R}-\mathrm{P0}: \mathrm{t}=-2.546, p=0.031$; P0-P1: $\mathrm{t}=2.894, p=0.018]$, aldosterone [R-P0: $\mathrm{t}=-3.823, p=0.004]$, and renin [R-P0: $\mathrm{t}=-4.606, p=0.001 ; \mathrm{P0}-\mathrm{P} 1: \mathrm{t}=4.26, p=0.003]$ ) showed significant differences with 3RINK.
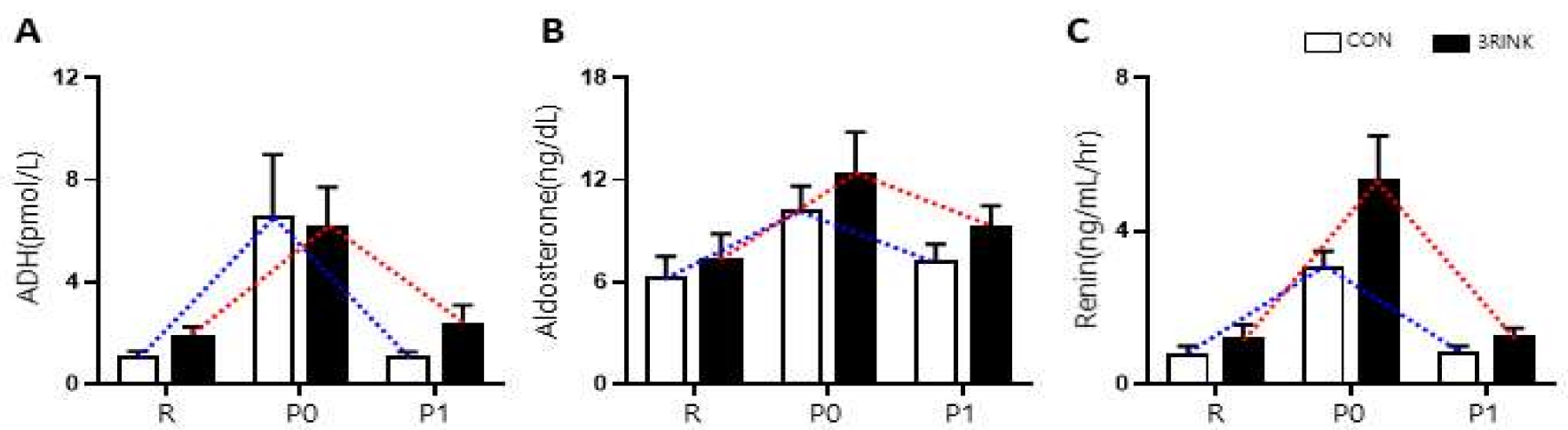

Figure 2. Changes in water regulating hormones according to the timing of fluid intake. Data for (A) ADH, (B) Aldosterone, (C) Renin represent the mean and SEM ( $n=10$ per group). $\mathrm{R}=$ Rest, $\mathrm{P} 0=$ Right after exercise, $\mathrm{P} 1=1 \mathrm{~h}$ after exercise.

\subsection{Differences in Body Electrolyte Composition According to the Type of Fluid and Time of Intake}

Figure 3 shows the results of the body electrolyte composition analysis according to the type of fluids and intake period. First, there was an interaction effect with the hematocrit $(\mathrm{F}=3.712, p=0.034)$. Therefore, as a result of a time-dependent analysis, $\mathrm{CON}$ (R-P0: $\mathrm{t}=-5.032, p=0.001 ; \mathrm{P0}-\mathrm{P} 1: \mathrm{t}=10.039, p=0.001)$ and 3RINK (R-P0: $\mathrm{t}=-15.127$, $p=0.001 ; \mathrm{P} 0-\mathrm{P} 1: \mathrm{t}=11.433, p=0.001)$ showed a statistically significant difference. In contrast, no interaction effect was observed for sodium, potassium, and hemoglobin; however, as a result of a time-dependent analysis, sodium (P0-P1: $\mathrm{t}=3.674, p=0.005)$, potassium (P0-P1: $\mathrm{t}=-3.000, p=0.015)$, and hemoglobin (R-P0: $\mathrm{t}=-5.361, p=0.001$; P0-P1: $t=10.091, p=0.001$ ) showed significant differences with CON. In addition, sodium (R-P0: $\mathrm{t}=-4$.163, $p=0.002 ; \mathrm{P} 0-\mathrm{P} 1: \mathrm{t}=3.343, p=0.001)$, potassium $(\mathrm{R}-\mathrm{P} 0: \mathrm{t}=4.881$, $p=0.001 ; \mathrm{P} 0-\mathrm{P} 1: \mathrm{t}=-6.011, p=0.015)$, and hemoglobin $(\mathrm{R}-\mathrm{P} 0: \mathrm{t}=-9.295, p=0.001$; P0-P1: $t=7.877, p=0.001$ ) showed significant differences after receiving 3RINK. Next, an analysis of the differences between the groups according to the timing of fluid consumption showed no statistically significant differences between groups for potassium, hemoglobin, and hematocrit, but there were differences between fluids for sodium (P0: $t=-3.008$, $p=0.008 ; \mathrm{P} 1: \mathrm{t}=-2.849, p=0.011$ ). Furthermore, the analysis of the difference in the amount of change between the time periods showed that the change between $\mathrm{R}$ and $\mathrm{P0}$ (P0-R) with 3RINK compared to that with CON was significant for sodium, hemoglobin, and hematocrit. There were no differences among the other variables. 
A

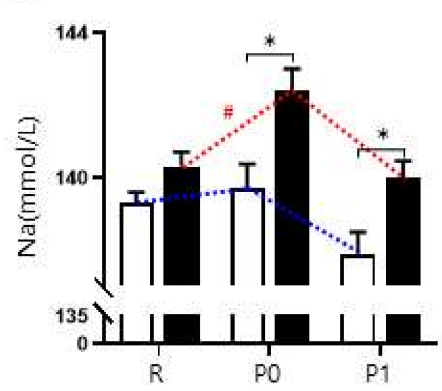

B

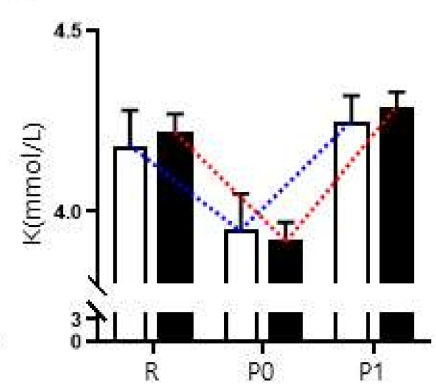

C

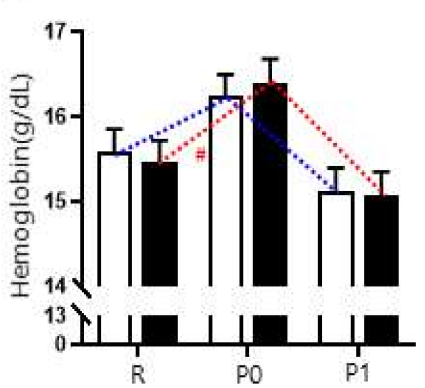

D

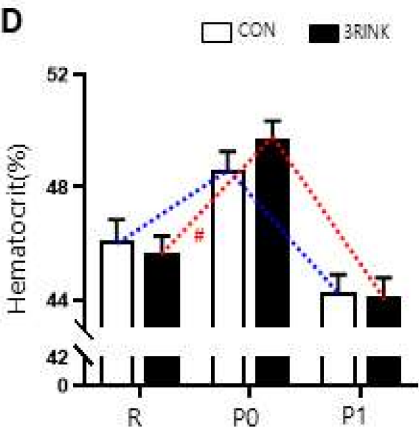

Figure 3. Changes in body electrolytes and hemoglobin/hematocrit according to the timing of fluid intake. Data for (A) Sodium, (B) Potassium (C) Hemoglobin (D) Hematocrit represent the mean and SEM ( $n=10$ per group). Significance for variance was denoted as ${ }^{*} p<0.05$, and differences (Blue and red dotted line) between groups for change over time were denoted as $\# p<0.05$. $\mathrm{R}=$ Rest, $\mathrm{P} 0=$ Right after exercise, $\mathrm{P} 1=1 \mathrm{~h}$ after exercise.

\subsection{The Difference in Aerobic Exercise Ability According to the Type of Fluid and Intake Period}

Table 3 shows the results of exercise capacity according to the type of fluid and intake period. The comparative analysis of exercise time, $\mathrm{VE}, \mathrm{VO}_{2} \max , \mathrm{RER}$, and $\mathrm{HRmax}$ between the groups showed no significant difference (time: $\mathrm{t}=-0.461, p=0.650$; VE: $\mathrm{t}=-0.812$, $p=0.428 ; \mathrm{VO}_{2}$ max: $\mathrm{t}=-0.280, p=0.783$; RER: $\mathrm{t}=0.103, p=0.919 ;$ HRmax: $\mathrm{t}=-1.393$, $p=0.186)$.

Table 3. Changes in exercise capacity.

\begin{tabular}{ccccc}
\hline Group & $\begin{array}{c}\text { CON } \\
(\boldsymbol{n}=\mathbf{1 0})\end{array}$ & $\begin{array}{c}\text { 3RINK } \\
(\boldsymbol{n}=\mathbf{1 0})\end{array}$ & $\mathbf{t}$ & $\boldsymbol{p}$ \\
\hline Time (s) & $767.00 \pm 109.75$ & $790.00 \pm 113.14$ & -0.461 & 0.650 \\
\hline $\mathrm{VE}(\mathrm{L} / \mathrm{min})$ & $123.16 \pm 20.96$ & $129.92 \pm 15.95$ & -0.812 & 0.428 \\
\hline $\mathrm{VO}_{2}$ max $(\mathrm{mL} \cdot \mathrm{min} \cdot \mathrm{kg})$ & $47.28 \pm 7.74$ & $48.28 \pm 8.25$ & -0.280 & 0.783 \\
\hline $\mathrm{RER}$ & $1.20 \pm 0.08$ & $1.19 \pm 0.05$ & 0.103 & 0.919 \\
\hline HRmax $(\mathrm{bpm})$ & $185.50 \pm 9.99$ & $190.50 \pm 5.35$ & -1.393 & 0.180 \\
\hline
\end{tabular}

VE: minute ventilation, $\mathrm{VO}_{2}$ max: maximum oxygen consumption, RER: respiratory exchange ratio, HRmax: maximum heart rate. Value are mean and SEM.

\subsection{The Difference in Recovery Ability According to the Type of Fluid and Time of Intake}

Figure 4 shows the results of the analysis of the recovery ability according to the type of fluid and intake period. The difference in recovery ability, as demonstrated by the lactic acid levels, according to the type of fluid and the time of intake, presented an interactive effect $(\mathrm{F}=4.612, p=0.013)$ (Table 4). Therefore, the results of the verification of the intergroup main effects showed significant differences between the fluids at $\mathrm{P} 0$ and $5 \mathrm{~min}$. In addition, statistically significant differences were found after receiving CON (RP0: $\mathrm{t}=-18.335, p=0.001 ; 5 \min -10 \mathrm{~min}: \mathrm{t}=2.876, p=0.018 ; 10-15 \mathrm{~min}: \mathrm{t}=2.536, p=0.032)$ and 3RINK (R-P0: $\mathrm{t}=-28.099, p=0.001 ; 5-10 \mathrm{~min}: \mathrm{t}=5.229, p=0.001 ; 10-15 \mathrm{~min}: \mathrm{t}=5.954$, $p=0.001)$ as a result of a time-dependent analysis. Next, upon analyzing the difference in the amount of change between the periods, 3RINK showed a significant difference in the change from $\mathrm{R}$ to $\mathrm{P0}(\mathrm{P} 0-\mathrm{R})$ and from 5 to $10 \mathrm{~min}$ (10 $\mathrm{min}-5 \mathrm{~min}$ ) compared to CON (P0-R: $\mathrm{t}=-3.941, p=0.001 ; 10 \mathrm{~min}-5 \mathrm{~min}: \mathrm{t}=2.236, p=0.038$ ). 


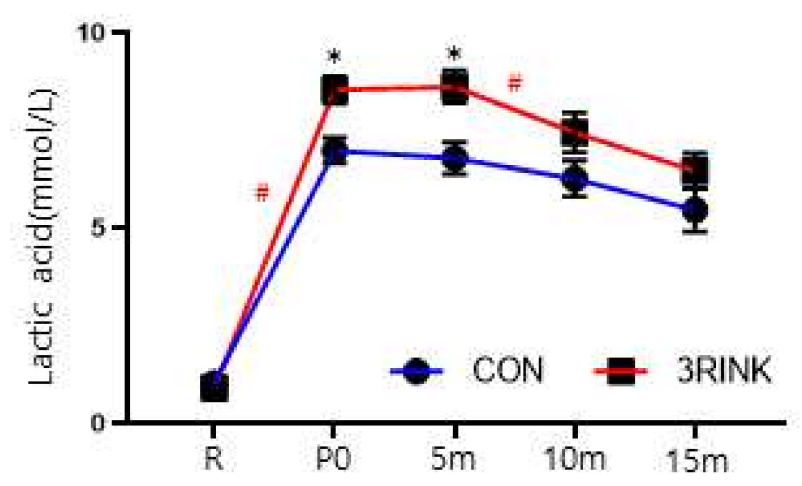

Figure 4. Changes in recovery ability according to the timing of fluid intake. Data represent the mean and SEM ( $n=10$ per group). Statistical significance for variance was denoted as $*<0.05$, and differences between groups for change over time were denoted as \# $p<0.05$. $\mathrm{R}=$ Rest, $\mathrm{P} 0=$ Right after exercise, $5 \mathrm{~m}=5 \mathrm{~min}$ after exercise, $10 \mathrm{~m}=10 \mathrm{~min}$ after exercise, $15 \mathrm{~m}=15 \mathrm{~min}$ after exercise.

Table 4. Changes in recovery ability.

\begin{tabular}{|c|c|c|c|c|c|c|c|c|c|}
\hline Variables & Group & $\mathbf{R}$ & P0 \# & $5 \mathrm{~m} \mathrm{\#}$ & $10 \mathrm{~m}$ & $15 \mathrm{~m}$ & & $\mathbf{F}$ & $p$ \\
\hline \multirow{2}{*}{$\begin{array}{c}\text { Lactic } \\
\text { acid } \\
(\mathrm{mmol} / \mathrm{L})\end{array}$} & $\begin{array}{c}\mathrm{CON} \\
(n=10)\end{array}$ & $\begin{array}{c}1.03 \pm \\
0.42\end{array}$ & $6.98 \pm 1.03 \$$ & $\begin{array}{c}6.78 \pm \\
1.30\end{array}$ & $\begin{array}{l}6.26 \pm \\
1.44+\end{array}$ & $\begin{array}{l}5.46 \pm \\
1.76 @\end{array}$ & $\mathrm{~T}$ & 263.360 & 0.001 * \\
\hline & $\begin{array}{l}\text { 3RINK } \\
(n=10)\end{array}$ & $\begin{array}{c}0.91 \pm \\
0.32\end{array}$ & $8.53 \pm 1.07 \$$ & $\begin{array}{c}8.61 \pm \\
1.28\end{array}$ & $\begin{array}{l}7.44 \pm \\
1.60 \dagger\end{array}$ & $\begin{array}{l}6.46 \pm \\
1.42 @\end{array}$ & G & 5.550 & 0.030 * \\
\hline
\end{tabular}

$\mathrm{R}=$ Rest, $\mathrm{P} 0=$ Right after exercise, $\mathrm{P} 1=1 \mathrm{~h}$ after exercise. Statistical significance was tested by repeated two-way ANOVA analysis of variances among groups at ${ }^{*} p<0.05$. $(\mathrm{T})=$ Time, $(\mathrm{G})=$ Froup, $(\mathrm{T} \times \mathrm{G})=$ Time $\times$ Group. $\# p<0.05$ vs. CON (independent $t$-test). $\$ p<0.05$ vs. $\mathrm{R} ;+p<0.05$ vs. $5 \mathrm{~m} ; @ p<0.05$ vs. $10 \mathrm{~m}$ (independent $t$-test). Values are mean and SEM.

\section{Discussion}

The purpose of this study was to determine efficient hydration by comparing body composition, water-regulating hormones, body electrolytes, and recovery ability after exhaustive exercise based on the intake of regular water compared to that after consuming an electrolyte drink before and after performing exhaustive exercise. The TBW was divided into approximately $60 \%$ ICW and approximately $40 \%$ ECW consisting of plasma and interstitial fluid. The TBW is very important for the maintenance of normal metabolism, oxygen and nutrients supply to the cells and removal of waste matter, and imbalances of TBW significantly affect health, which are related to kidney disease, circulatory system diseases among others [1]. Exercise is known to cause a serious imbalance in the ICW and ECW because of a decreased plasma volume, increased body temperature, and increased blood osmotic pressure [20]. Therefore, it is necessary to prevent ICW and ECW imbalance and dehydration during exercise through the intake of appropriate fluids. According to the results of this study, the type of fluid consumed had a differential effect on the reduction of ICW and ECW between rest and immediately after exercise and in the recovery from exercise.

The factors limiting efficient exercise capacity include dehydration, energy depletion, and fatigue caused by metabolic by-products, such as lactic acid [21]. In this study, the TBW and urine levels showed no significant difference between rest and immediately after exercise, while the TBW, ICW, ECW, and urine levels showed no significant difference between $1 \mathrm{~h}$ after exercise and immediately after exercise with CON. However, after consuming 3RINK there was a positive trend in all values after exercise. In a study by Nielsen et al. [22], six adult male individuals were exposed to exercise-induced dehydration. The group was divided into groups ingesting control, glucose, $\mathrm{NaCl}$, and $\mathrm{KCl}$ drinks, and 
the body components were analyzed at $2 \mathrm{~h}$ after ingestion. The TBW, ICW, and ECW were significantly higher when a $\mathrm{NaCl}$ drink was ingested compared to the corresponding values in the control drink group, in line with the results of this study. In addition, a study by Maughan et al. [23] examined eight adult male individuals who were exposed to dehydration with an equivalent of $2 \%$ BW loss. The group received glucose, sodium, potassium, or chloride drinks with no difference in the amount of weight loss. Cumulative urine volumes were higher in the group that ingested glucose drinks that did not contain electrolytes, which is consistent with our findings. These results suggested that electrolyte drinks can prevent water loss in the body by increasing water retention and reducing urine volume during dehydration associated with exercise [5,24].

Body water loss due to exercise is regulated by a water-regulating hormone that responds to changes in body water to maintain water homeostasis [25]. Renin, a body water-regulating hormone, is a type of proteinase released from the renal glomeruli as a response to hypernatremia associated with TBW loss. Renin secretion is known to increase the secretion of aldosterone, an adrenal cortex hormone, and to regulate water balance by stimulating the secretion of ADH released from the posterior pituitary gland [26].

In this study, after consuming regular water and an electrolyte drink before and after exercise, ADH, aldosterone, and renin did not show an interaction effect between the different periods of intake and types of fluids. Hormone concentrations showed a tendency to increase at P0 and, then, decreased again at P1, with no significant difference between the CON and 3RINK groups. Woo and Paik [27] reported that there was no change in the secretion of renin and aldosterone upon ingestion of fluids with different sodium concentrations after treadmill exercise-induced dehydration in five male college students. In a study by Park et al. [28] involving 11 adult male individuals, consuming electrolyte drinks before and after performing exhaustive exercise did not induce any changes in $\mathrm{ADH}$. These findings were consistent with the results of this study and were attributed to the intake of sodium contained in the electrolyte drinks, which abolishes the hyponatremic trigger for secretion of renin and aldosterone. In addition, at P1, ADH was found to be higher in the 3RINK than in the CON group. This could be conducive in the maintenance of water homeostasis because of increased water reabsorption and reduced urine excretion $[5,24]$.

Electrolyte balance is required to maintain normal cell function and plasma volume. Sodium, which is abundantly present in the ECW, plays a role in maintaining plasma volume and osmotic equilibrium between the ECW and the ICW. Potassium is an electrolyte present in the ICW that helps regulate osmotic pressure and plays an important role in nerve stimulation and muscle contraction [29]. Our analysis of body water and electrolytes after consuming the two types of fluids before and after exercise revealed a significant difference in terms of sodium levels at P0 and P1. In addition, a significant difference was found in P0-R for the sodium, hemoglobin, and hematocrit levels with 3RINK intake. In a study by Lee [30], five male college students received glycerol-enriched water and regular water at $2 \mathrm{~h}$ before exercise. Sodium and potassium were found to be significantly increased in the group that received glycerol-enriched water. Although a reduction in sodium concentration was observed due to the release of sweat during exercise, the levels were more stable in the glycerol than in the regular water group by the end of the exercise, suggesting increased water retention in the body and increased ion reabsorption. In contrast to the results of the above study, our study showed that sodium increased at P0, and decreased to a level similar to that at rest at P1. In addition, at P1 there was a significant increase after receiving 3RINK compared to that after receiving CON. The amount of water that exits into the interstitial water to maintain plasma osmotic pressure leads to a decrease in water loss and increase in absorption [31]. Therefore, unlike the intake of regular water, electrolyte water allows quick recovery of the loss of body water by increasing water absorption rate, which faciliates rebalancing of water homeostasis.

Hemoglobin, which carries oxygen, and hematocrit, which indicates the ratio of red blood cells in the blood, are used as indicators of plasma volume and are important factors 
in exercise performance [32,33]. Although there was no significant difference between the groups in this study, these variables showed an increasing tendency with 3RINK compared to $\mathrm{CON}$ at $\mathrm{P} 0$ followed by a decrease at P1. This indicated an increased capacity for oxygen transport during exercise because of the intake of electrolyte drinks, which can be interpreted as having a positive effect in faciliating muscle recovery [34]. Maintenance of plasma volume is an essential factor for adequate exercise performance, and it has been reported that an increased plasma volume consequently increases cardiac output and maximal oxygen uptake [35]. In the case of high-intensity exercise, the accumulation of lactic acid in the body during energy metabolism causes a decrease in exercise capacity and delays recovery. A recent study reported that proper electrolyte supplementation can maintain body function, delay the onset of exercise fatigue, and improve exercise performance, as electrolytes in the body are lost along with body water during exercise [36].

This study compared and analyzed exercise time, ventilation per minute, maximum oxygen intake, breathing exchange rate, and maximum heart rate after consuming regular water versus an electrolyte drink before and after exercise. Our findings showed improved exercise capacity, as measured by the maximum oxygen intake with 3RINK compared to that after consuming CON. In addition, an analysis of the difference in recovery ability, as reflected by the blood lactic acid concentration, showed interaction effects between periods of intake and type of fluids. In particular, immediately after exercise and at $5 \mathrm{~min}$ after exercise, significant differences between the intake of fluids were observed, and the difference between $5 \mathrm{~min}$ and $10 \mathrm{~min}$ after exercise ( $10 \mathrm{~min}-5 \mathrm{~min}$ ) was also significant between the groups. A recent study by Park et al. [28] reported the effects of exercise after consuming an electrolyte drink versus regular water in 11 adult male individuals. The exercise time and maximum oxygen intake significantly increased in the electrolyte drink group compared to the group that consumed regular water, and their blood lactate concentration was higher than that of the regular water group immediately after and at $30 \mathrm{~min}$ after exercise. In another study, eight male college students were asked to exercise to achieve dehydration equivalent to $2 \%$ of BW loss after being divided into the non-intake, general-water intake, and electrolyte-drink groups. Exercise performance time increased in the group that consumed the electrolyte drink [37]. Therefore, the reason that the serum concentration of lactic acid with 3RINK was higher than that with CON was the increase in exercise capacity with 3RINK. In addition, the fact that lactic acid concentration decreased faster with 3 RINK than with CON at 5 min after exercise can be interpreted as an indication that the ingestion of electrolyte water facilitates recovery. Therefore, the increased lactic acid removal could be attributed to an accelerated movement of lactic acid to the tissues by increasing the amount of plasma with electrolyte drinks. Moreover, carbohydrates and sugar components included in the electrolyte drinks supplemented blood glucose to quickly remove lactic acid after exercise [38].

\section{Conclusions}

Our study revealed the following important findings after comparing body composition, water-regulating hormones, body electrolytes, and recovery ability based on the intake of regular and electrolyte water before and after performing exhaustive exercise. First, body composition was significant in BFM $(p=0.035)$, ICW $(p=0.016)$, ECW $(p=0.008)$ when CON and 3RINK were compared in the time interval between $\mathrm{R}$ and $\mathrm{P} 0$ ( $\mathrm{P} 0-\mathrm{R})$. In addition, the difference between P1 and P0 showed positive trends in BW, ICW, ECW, and urine levels. Second, the water-regulating hormones, such as ADH, aldosterone, and renin did not show interaction effects between the different periods of intake and groups. Third, the analysis of the difference in the amount of change between the time periods showed that the change between $\mathrm{R}$ and $\mathrm{P0}(\mathrm{PO}-\mathrm{R})$ after consuming 3RINK compared to that after consuming CON was significant for the sodium $(p=0.028)$, hemoglobin $(p=0.001)$, and hematocrit $(p=0.016)$ levels. Fourth, the intake of electrolyte beverages improved according to the exercise time, ventilation per min, maximum oxygen intake, breathing exchange rate, and maximum heart rate. Finally, recovery availability was confirmed through lactic 
acid concentration. As a result of analyzing the difference in the amount of change by period, 3RINK showed a significant difference in the change from R to P0 (P0-R) and from 5 to $10 \mathrm{~min}$ compared to after $\mathrm{CON}$ intake. Taken together, these results suggested that the intake of electrolyte water is more effective than the intake of regular water in preventing a decrease in BW and serum electrolytes. Moreover, it is more effective in improving exercise ability and recovery ability. In the future, it is necessary to further determine the effects of electrolyte beverages in terms of adjusting for electrolyte components, timing of intake, and participants' conditioning (i.e., athletes vs. the general public).

Author Contributions: Experiment design, performance, and analysis, D.-H.C.; experiment design and interpretation J.-Y.C., J.-H.K. and T.-K.K.; writing, D.-H.C. and T.-K.K. All authors acknowledged responsibility for the full content of the submitted manuscript and approved their submission. All authors have read and agreed to the published version of the manuscript.

Funding: This research was funded by INTERFOREST Inc.

Institutional Review Board Statement: The study was conducted according to the guidelines of the Declaration of Helsinki, and approved by the Institutional Review Board of Korea National Sports University (1263-202103-BR-004-01).

Informed Consent Statement: Informed consent was obtained from all subjects involved in the study.

Conflicts of Interest: The authors declare no conflict of interest.

\section{References}

1. Kelley, G.A.; Kelley, K.S. Progressive resistance exercise and resting blood pressure : A meta-analysis of randomized controlled trials. Hypertension (Dallas, TX: 1979) 2000, 35, 838-843. [CrossRef] [PubMed]

2. Armstrong, L.E.; Johnson, E.C. Water Intake, Water Balance, and the Elusive Daily Water Requirement. Nutrients 2018, 10, 1928. [CrossRef]

3. Sawka, M.N.; Cheuvront, S.N.; Kenefick, R.W. Hypohydration and Human Performance: Impact of Environment and Physiological Mechanisms. Sports Med. (Auckl., N. Z.) 2015, 45 (Suppl. 1), S51-S60. [CrossRef]

4. Hew, T.D.; Chorley, J.N.; Cianca, J.C.; Divine, J.G. The incidence, risk factors, and clinical manifestations of hyponatremia in marathon runners. Clin. J. Sport Med. Off. J. Can. Acad. Sport Med. 2003, 13, 41-47. [CrossRef] [PubMed]

5. Rehrer, N.J. Fluid and electrolyte balance in ultra-endurance sport. Sports Med. (Auckl., N. Z.) 2001, 31, 701-715. [CrossRef]

6. Casa, D.J.; Ganio, M.S.; Lopez, R.M.; McDermott, B.P.; Armstrong, L.E.; Maresh, C.M. Intravenous versus Oral Rehydration Physiological, Performance, and Legal Considerations. Curr. Sports Med. Rep. 2008, 7, 541-549. [CrossRef]

7. Glace, B.W.; Murphy, C.A.; McHugh, M.P. Food intake and electrolyte status of ultramarathoners competing in extreme heat. J. Am. Coll. Nutr. 2002, 21, 553-559. [CrossRef] [PubMed]

8. Bürge, J.; Knechtle, B.; Knechtle, P.; Gnädinger, M.; Rüst, C.A.; Rosemann, T. Maintained serum sodium in male ultra-marathonersthe role of fluid intake, vasopressin, and aldosterone in fluid and electrolyte regulation. Horm. Metab. Res. 2011, 43, 646-652. [CrossRef]

9. Wemple, R.D.; Morocco, T.S.; Mack, G.W. Influence of sodium replacement on fluid ingestion following exercise-induced dehydration. Int. J. Sport Nutr. 1997, 7, 104-116. [CrossRef]

10. Montain, S.J.; Sawka, M.N.; Wenger, C.B. Hyponatremia associated with exercise: Risk factors and pathogenesis. Exerc. Sport Sci. Rev. 2001, 29, 113-117. [CrossRef]

11. Lim, I.S. The changes of electrolyte and fluid-regulating hormones concentration in the collapsed runners during marathon race. Korean J. Phys. Educ. 2006, 45, 489-499.

12. Shirreffs, S.M. Conference on "Multidisciplinary approaches to nutritional problems". Symposium on "Performance, exercise and health". Hydration, fluids and performance. Proc. Nutr. Soc. 2009, 68, 17-22. [CrossRef]

13. Park, S.H.; Jeon, B.Y.; Kim, Y.H.; Yoon, J.H. The Effects of 5-weeks Electrolyte Beverage Ingestion on Blood Electrolyte Concentration, Cardiac Muscle Damage Index and Exercise Performance during Acute Exercise in Hot Environment. J. Korean Soc. Living Environ. Syst. 2017, 24, 608-615. [CrossRef]

14. Sims, S.T.; Rehrer, N.J.; Bell, M.L.; Cotter, J.D. Preexercise sodium loading aids fluid balance and endurance for women exercising in the heat. J. Appl. Physiol. (Bethesda, Md.: 1985) 2007, 103, 534-541. [CrossRef]

15. Petróczi, A.; Naughton, D.P. Supplement use in sport: Is there a potentially dangerous incongruence between rationale and practice? J. Occup. Med. Toxicol. (Lond., Engl.) 2007, 2, 4. [CrossRef]

16. Hamouti, N.; Fernández-Elías, V.E.; Ortega, J.F.; Mora-Rodriguez, R. Ingestion of sodium plus water improves cardiovascular function and performance during dehydrating cycling in the heat. Scand. J. Med. Sci. Sports 2014, 24, 507-518. [CrossRef] [PubMed] 
17. Kim, T.Y.; Kim, K.S. The effects of supplementary fluid ingestion on lactate and electrolytes after maximal exercise. J. Kwangju Health Coll. 2000, 25, 279-294.

18. Hoffman, M.D.; Stuempfle, K.J. Is Sodium Supplementation Necessary to Avoid Dehydration During Prolonged Exercise in the Heat? J. Strength Cond. Res. 2016, 30, 615-620. [CrossRef]

19. James, L.J.; Mears, S.A.; Shirreffs, S.M. Electrolyte supplementation during severe energy restriction increases exercise capacity in the heat. Eur. J. Appl. Physiol. 2015, 115, 2621-2629. [CrossRef]

20. Fortney, S.M.; Wenger, C.B.; Bove, J.R.; Nadel, E.R. Effect of hyperosmolality on control of blood flow and sweating. J. Appl. Physiol. Respir. Environ. Exerc. Physiol. 1984, 57, 1688-1695. [CrossRef] [PubMed]

21. Murray, R.; Paul, G.L.; Seifert, J.G.; Eddy, D.E. Responses to varying rates of carbohydrate ingestion during exercise. Med. Sci. Sports Exerc. 1991, 23, 713-718. [CrossRef] [PubMed]

22. Nielsen, B.; Sjøgaard, G.; Ugelvig, J.; Knudsen, B.; Dohlmann, B. Fluid balance in exercise dehydration and rehydration with different glucose-electrolyte drinks. Eur. J. Appl. Physiol. Occup. Physiol. 1986, 55, 318-325. [CrossRef] [PubMed]

23. Maughan, R.J.; Owen, J.H.; Shirreffs, S.M.; Leiper, J.B. Post-exercise rehydration in man: Effects of electrolyte addition to ingested fluids. Eur. J. Appl. Physiol. Occup. Physiol. 1994, 69, 209-215. [CrossRef] [PubMed]

24. Noakes, T. Hyponatremia in distance runners: Fluid and sodium balance during exercise. Curr. Sports Med. Rep. 2002, 1, 197-207. [CrossRef]

25. Smith, M.S.; Dyson, R.; Hale, T.; Harrison, J.H.; McManus, P. The effects in humans of rapid loss of body mass on a boxing-related task. Eur. J. Appl. Physiol. 2000, 83, 34-39. [CrossRef]

26. Maresh, C.M.; Gabaree-Boulant, C.L.; Armstrong, L.E.; Judelson, D.A.; Hoffman, J.R.; Castellani, J.W.; Kenefick, R.W.; Bergeron, M.F.; Casa, D.J. Effect of hydration status on thirst, drinking, and related hormonal responses during low-intensity exercise in the heat. J. Appl. Physiol. (Bethesda, Md.: 1985) 2004, 97, 39-44. [CrossRef]

27. Woo, J.H.; Paik, I.Y. Different Sodium Concentration Fluid Supplement on Fluid Regulation Hormone Changes During Exercise. Korean J. Phys. Educ. 1999, 38, 551-561.

28. Park, S.H.; Jeon, B.Y.; Kim, Y.H.; Yoon, J.H. Effects of Deep-sea Water Electrolyte Supplement on Blood Electrolyte Concentration and Exercise Performance during Acute Exercise in Hot Environment. Korean Soc. Living Environ. Syst. 2016, $23,835-842$. [CrossRef]

29. Anderson, R.A.; Guttman, H.N. Trace Minerals and Exercise. In Exercise, Nutrition, and Energy Metabolism; Macmillan: New York, NY, USA, 1988.

30. Lee, S.B. The effects of ingestion of water or glycerol on renin activity, rectum temperature, blood electrolytes concentration in exercise. J. Life Sci. 2008, 18, 187-192. [CrossRef]

31. Nose, H.; Mack, G.W.; Shi, X.R.; Nadel, E.R. Role of osmolality and plasma volume during rehydration in humans. J. Appl. Physiol. (Bethesda, Md.: 1985) 1988, 65, 325-331. [CrossRef]

32. Dill, D.B.; Costill, D.L. Calculation of percentage changes in volumes of blood, plasma, and red cells in dehydration. J. Appl. Physiol. 1974, 37, 247-248. [CrossRef] [PubMed]

33. Brotherhood, J.; Brozović, B.; Pugh, L.G. Haematological status of middle- and long-distance runners. Clin. Sci. Mol. Med. 1975, 48, 139-145. [CrossRef] [PubMed]

34. Kim, K.J.; Ahn, N.Y.; Shin, Y.J. Effects of ambient temperature and exercise duration on hematocrit value and rectal temperature during submaximal exercise in obese. J. Coach. Dev. 2005, 22, 79-86.

35. Berger, N.J.; Campbell, I.T.; Wilkerson, D.P.; Jones, A.M. Influence of acute plasma volume expansion on VO2 kinetics, VO2 peak, and performance during high-intensity cycle exercise. J. Appl. Physiol. (Bethesda, Md.: 1985) 2006, 101, 707-714. [CrossRef]

36. Zhang, Q. Effect of Electrolyte Beverage on Exercise Ability of Human Body. Food Ind. 2018, 39.

37. Paik, I.Y.; Suh, S.H.; Jin, H.E.; Kim, Y.I.; Woo, J.H. Effects of different fluid supplement following dehydration on sleep efficiency and consequent exercise performance. Korean J. Phys. Educ. 2007, 46, 427-436.

38. Hubbard, R.W. Influence of thirst and fluid palatability on fluid ingestion during exercise. Perspect. Exerc. Sci. Sports Med. 1990, 3, 39-95. 